\title{
Synthesis of Tris(4,7-diphenyl-1,10-phenanthroline)Ruthenium(II) Chloride
}

The complex was synthesized in a commercial microwave oven CEM, Discover system using septum-sealed $10 \mathrm{ml}$ glass tube. In a typical reaction dichloro(p-cymene)ruthenium(II)dimer (0.0612 g, 0.1 mmol, Aldrich) and 4,7-diphenyl-1,10-phenanthroline (0.233 g, 0.7 mmol, Aldrich) in $2 \mathrm{ml}$ of DMF were subjected to $300 \mathrm{~W}$ microwave source at $250^{\circ} \mathrm{C}$ for 5 minutes. After cooling the reaction tube, the complex was precipitated using $2 \mathrm{ml}$ dichloromethane and $5 \mathrm{ml}$ diethyl ether. The isolated bright red-orange solid was further re-crystallized using dichloromethane and diethyl ether, yielding (0.207 g) 89\%. The UV/Vis absorption spectrum of the complex in ethanol shows peaks at $465\left(\varepsilon=3.45 \times 10^{4} \mathrm{M}^{-1} \mathrm{~cm}^{-1}\right), 440\left(\varepsilon=3.48 \times 10^{4} \mathrm{M}^{-1} \mathrm{~cm}^{-1}\right)$ and $280 \mathrm{~nm}(\varepsilon=15.09$ $\left.\mathrm{x} 10^{4} \mathrm{M}^{-1} \mathrm{~cm}^{-1}\right)$. The complex upon excitation at $465 \mathrm{~nm}$ exhibits an intense bright orange luminescence maximum at $605 \mathrm{~nm}$ consistent with the literature.

NMR spectral data:

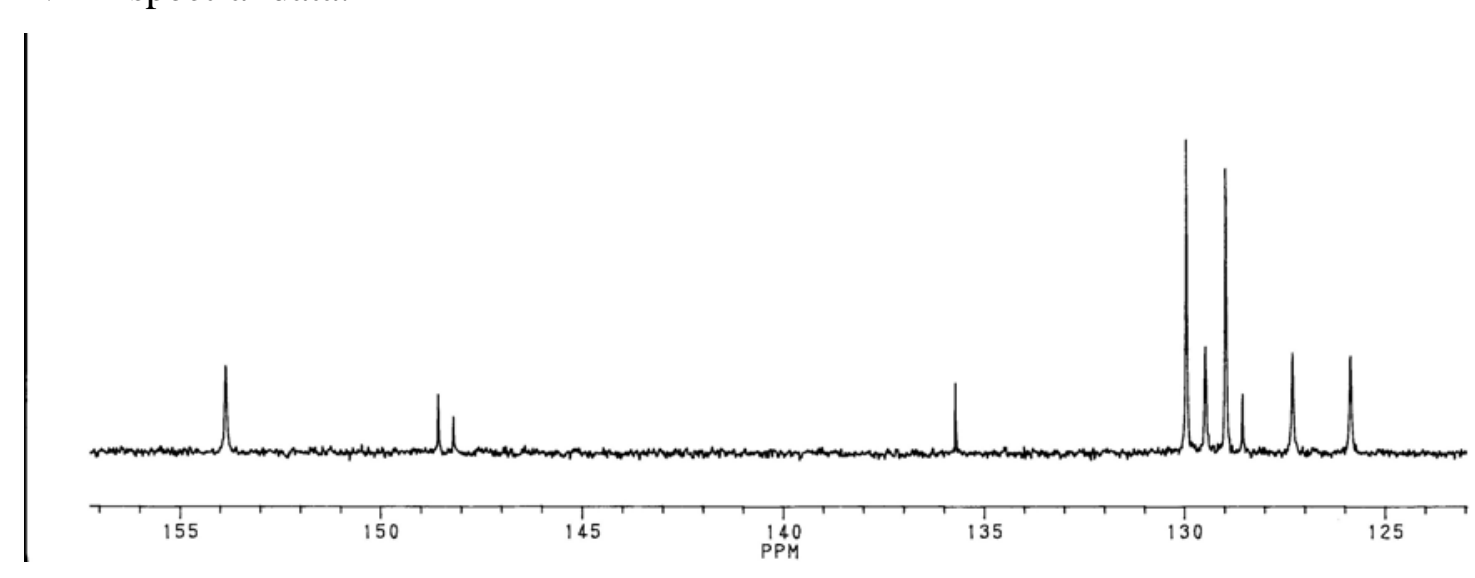

A portion of the ${ }^{13} \mathrm{C}$ NMR spectrum of the tris(4,7-diphenyl-1,10phenanthroline)ruthenium(II) chloride complex measured in $\mathrm{CDCl}_{3}$

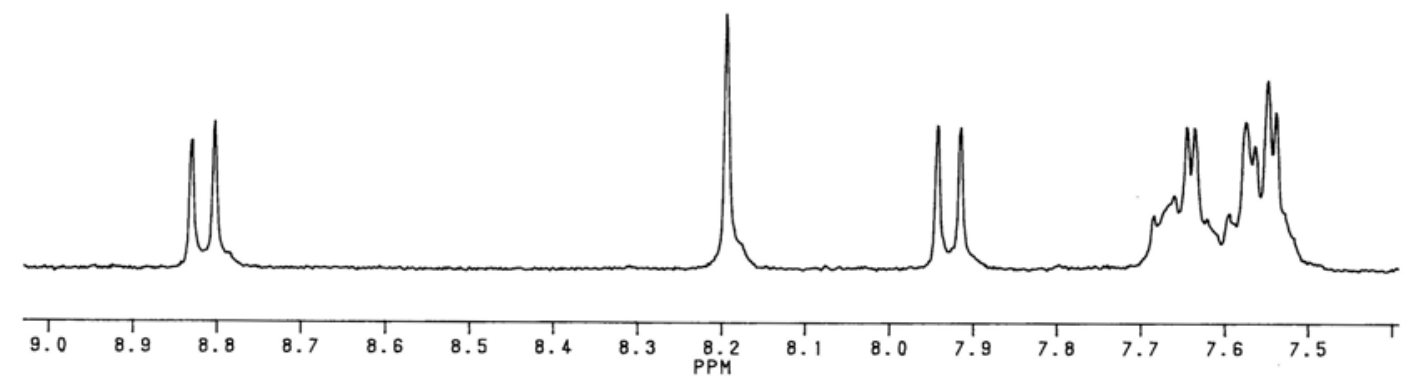

A portion of the proton ${ }^{1} \mathrm{H}$ NMR spectrum of the tris(4,7-diphenyl-1,10phenanthroline)ruthenium(II) chloride complex measured in $\mathrm{CDCl}_{3}$ 